\title{
PEDAGOGIA DA ALTERIDADE: O ENSINO COMO CONDIÇÃO ÉTICO-CRÍTICA DO SABER EM LEVINAS
}

\author{
Marcos AleXandre Alves* \\ GOMERCINDO GHIGGI*
}

\begin{abstract}
RESUMO: Este artigo estabelece, a partir do pensamento de Levinas, uma aproximação entre ética e educação. $\mathrm{O}$ texto apresenta uma reavaliação do pensamento ocidental, desde a crítica à pedagogia da totalidade, ensinada pela maestria do autor, no sentido de rever a primazia do ensino fundado no saber técnico-instrumental, bem como enfatiza, a partir da racionalidade ética, novas vias para pensar e enfrentar os desafios da educação contemporânea, notadamente, marcada pela crise da unidade da razão e da constituição da subjetividade soberana. A grande contribuição de Levinas, para a educação, consiste na defesa de outra modalidade pedagógica, outro modo de ensino, fundada no acolhimento e na abertura ao ensinamento proveniente da alteridade, como condição ético-crítica do saber.
\end{abstract}

Palavras-chave: Alteridade. Educação. Pedagogia. Ensino. Ética.

\section{Pedagogy of alterity: teaching as a Condition of KNowledge CRITICAL AND ETHICAL IN LEVINAS}

\begin{abstract}
This article establishes, from the thought of Levinas, a connection between ethics and education. The paper presents a revaluation of western thought, from the critical to pedagogy of Totality, taught by mastery of the Same, to revise the primacy of teaching based on the technicalinstrumental, and emphasizes, from the ethical rationality, new avenues to think and face the challenges of contemporary education, notably, the crisis marked by the unity of reason and the constitution of sovereign subjectivity. Levinas's great contribution to education is the defense of another pedagogical modality, other mode of teaching, founded in welcoming and opening to the teaching from the alterity as a condition of knowledge critical and ethical.
\end{abstract}

Key words: Alterity. Education. Pedagogics. Teaching. Ethics.

\footnotetext{
* Doutor em Educação e professor adjunto do Centro Universitário Franciscano (Santa Maria, RS). E-mail: marcosalves@unifra.br

** Doutor em Educação e professor associado da Universidade Federal de Pelotas (Ufpel). E-mail: gghiggi@terra.com
} 


\title{
PÉdAgogie de L'Altérité: L'ENSEIGNEMENT COMME CONDition DE CRITIQUE ÉTHIQUE DU SAVOIR DANS LEVINAS
}

\begin{abstract}
RÉSUMÉ: Cet article établit, à partir de la pensée de Levinas, un rapprochement entre éthique et éducation. Le texte présente un ré-examen de la pensée occidentale, de la critique à la pédagogie de la Totalité, enseignée par la maîtrise du Même, au sens de réviser la primauté de l'enseignement fondé dans le savoir technique instrumental, aussi bien qu'il souligne, à partir de la rationalité éthique, de nouvelles voies à penser et incite à relever les défis de l'éducation contemporaine, notamment, marquée par la crise de l'unité de la raison et de la constitution de la subjectivité souveraine. La grande contribution de Levinas à l'éducation, est la défense d'une autre modalité pédagogique, une autre façon d'enseigner, fondée sur l'accueil et l'ouverture à $\mathrm{l}^{\prime}$ enseignement provenant de l'altérité comme condition éthico-critique du savoir.
\end{abstract}

Mots-clés: Altérité. Éducation. Pédagogie. Enseignement. Éthique.

\section{Introdução}

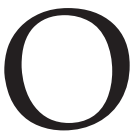

presente texto estrutura-se, sobretudo, a partir da obra Totalité et infini (1961) do filósofo contemporâneo Emmanuel Levinas, bem como serve-se de alguns comentadores do pensamento do referido autor, em vista de uma aproximação de sua contribuição filosófica com a educação. Temos a convicção de que este empreendimento não é fácil, uma vez que Levinas não escreveu, especificamente, um texto voltado para a educação. Nesse sentido, a incursão que empreendemos é feita por conta própria, o que pode gerar, aos olhos de alguns estudiosos do pensamento levinasiano, uma deturpação da genuinidade da meditação deste filósofo. Contudo, acreditamos que o pensamento de Levinas, no tocante à racionalidade ética, pode contribuir para se repensar a educação contemporânea.

Em busca desta aproximação entre ética e educação, nos movemos, por um lado, na tentativa de uma reavaliação do pensamento ocidental, a partir da crítica à pedagogia da totalidade ensinada pela maestria deste filósofo, ou ainda a partir da tentativa de abalar o ensino fundado no saber técnico-instrumental, presente na base desta tradição. Por outro lado, buscaremos demonstrar que Levinas não é só um crítico da tradição filosófico-pedagógica ocidental, mas também vislumbra e abre vias para se pensar os desafios da educação contemporânea, notadamente, marcada pela crise da unidade da razão e pela destituição de toda e qualquer subjetividade soberana. Assim, neste artigo, defenderemos que a grande contribuição de Levinas para a educação, consiste na (re)significação ou resgate de uma outra modalidade pedagógica, outro-modo-que-ser pedagógico, um outro modo de ensino, fundamentalmente metafísico. Ou seja, de uma pedagogia fundada no ensinamento proveniente do Outro, como condição ético-crítica do saber. Portanto, mostraremos, 
a partir da esteira do pensamento de Levinas, que é possível pensar as bases sobre as quais se estrutura uma matriz de educação, em nosso juízo, humanizadora, pautada no acolhimento do Outro na sua infinitude. Nesse sentido, acreditamos que Levinas defende, em última análise, uma pedagogia do acolhimento responsável de outrem. Essa pedagogia da responsabilidade exige um compromisso ético, que se traduz em acolhimento da alteridade.

O pensamento de Levinas se constitui como uma tentativa de pôr em questão o primado do saber, da atitude intelectual, que se apoia na autorreflexão como instância última de sentido para a filosofia e a educação. Por outro lado, seu discurso defende, em linguagem grega, um tipo de relação ético-pedagógica entre o Mesmo e o Outro, segundo o qual a autorreflexão da razão não consegue assimilar, apropriar e esgotar a alteridade do Outro. Nesse sentido, sua proposta ético-pedagógica defronta-se com a filosofia ocidental como um todo, pois esta sempre se caracterizou pela redução do Outro ao Mesmo.

Por conseguinte, Levinas coloca em questão o ensino proporcionado pelo saber filosófico, como sistema teórico, que perfaz um movimento de assimilação de uma identidade às voltas com a diferença. Em suma, nosso filósofo questiona esta intenção da filosofia em transformar todo o diferente em idêntico, ou ainda em pensar a transcendência a partir da imanência. Frente a esta suprassunção da diferença pela identidade, Levinas lança mão do conceito de ensino, como possibilidade para questionar a autossuficiência e a violência presentes na ontologia. $\mathrm{O}$ ensino, tomado em sentido metafísico, permite valorizar o Outro enquanto tal e, consequentemente, fundar a ética sobre uma relação irredutível ao conceito. O ensino, em Levinas, implica uma saída de si que não visa ao retorno, à segurança ou à satisfação.

\section{A dimensão ético-pedagógica do saber}

Para Levinas, a esfera de sentido chamada ontologia, pedagogia tradicional, não é a única e nem a privilegiada para se pensar a relação humana, pois a verdadeira pedagogia como relação com Outrem pressupõe um laço irredutível ao ato representacional e compreensivo. Isto é, na relação com Outrem, articula-se um chamamento irredutível a um ato intencional: "A relação com Outrem, portanto, não é ontologia. Este vínculo com Outrem que não se reduz à representação de Outrem, mas à invocação, e onde a invocação não é precedida de compreensão, chamo-a religião" (Levinas, 1997, p. 29).

Levinas utiliza o termo "religião"1 para pensar a descrever a relação éticopedagógica como irredutível à intencionalidade teórica. No entanto, este encontro com Outrem (religião) não envolve uma participação no sagrado, em Deus ou no 
próprio ser. Vale dizer, esta relação não se descreve mediante o conhecimento ou experiência mística ou religiosa. Trata-se, pois, de uma relação entre os seres humanos, que desponta como algo totalmente irredutível ao conhecimento e à representação, uma relação que respeita e resguarda a alteridade do Outro enquanto Outro. Esta relação, descrita a partir do termo religião, pedagogia ética, questiona qualquer forma de assimilação do Outro pelo Mesmo, isto é, dilacera o esforço que o Eu possui de constituir uma totalidade.

Ao escolher o termo religião (Levinas) - sem ter pronunciado a palavra Deus nem a palavra sagrado - pensa primeiro no sentido que lhe confere Augusto Comte no início de sua Politique Positive. Nenhuma teologia, nenhuma mística se dissimula por detrás da análise que acaba de fazer do encontro com Outrem e do qual lhe interessa sublinhar a estrutura formal. O objeto do encontro é ao mesmo tempo dado a nós e em sociedade conosco, sem que este acontecimento de socialidade possa reduzir-se a uma propriedade qualquer a se revelar no dado, sem que o conhecimento deva contudo anunciar que a relação com homens, irredutível à compreensão, se afasta por isso mesmo do exercício de poder. (Idem, ibid., p. 29)

Ao tomar a religião, pedagogia ética, como a única e verdadeira relação com Outrem, e para além de qualquer tipo de recurso à racionalidade teórica, Levinas estabelece outro horizonte de significação. Significação esta proveniente do sentido primeiro e anterior a tudo o mais, vale dizer, o sentido ético. Este, enquanto verdadeiro sentido ou sentido que se apresenta de forma eminente, é produto de um tipo de relação que a cada momento questiona o poder e a luz do conhecimento:

Esta relação não é pré-filosófica, porque não violenta o eu, não lhe é imposta brutalmente de fora, contra a sua vontade, ou com o seu desconhecimento como opinião; mais exatamente, é-lhe imposta, para além de toda a violência, de uma violência que o põe inteiramente em questão. A relação ética, oposta à filosofia primeira da identificação da liberdade e do poder, não é contra a verdade, dirige-se ao ser na sua exterioridade absoluta e cumpre a própria intenção que anima a caminhada para a verdade. (Levinas, 2000, p. 34)

Esta colocação em questão do poder da luz do conhecimento, da pedagogia iluminista, de modo algum, nos alerta Levinas, deve ser tomada e entendida como um processo refratário ao estatuto racional, isto é, como meramente irracional. Este pôr o Logos em questão não é o mesmo que cair nas malhas da desrazão, senão um esforço permanente para pensar para além do que o racional pode abarcar, pois o racional, enquanto compreensão e representação, não consegue esgotar e abarcar a alteridade de Outrem. Alhures, na esteira levinasiana, é preciso evitar, também, os encalços de um processo irracional como esfera última de sentido, uma vez que a ingenuidade destrói a alteridade de Outrem tanto quanto o registro teórico ou racional. 
Ao apresentar a filosofia e pedagogia tradicional, como discurso do Mesmo (ontologia), Levinas almeja questionar a sua pretensão dominadora, seu propósito de apropriar-se de tudo o que é outro. No fundo, o objetivo de Levinas é questionar a primazia pedagógica do saber teórico, para salvaguardar e lutar contra a transformação do primado da diferença em indiferença. Esta pedagogia de identificação ontológica, segundo Levinas,

(...) exige a mediação, o recurso aos Neutros. Para compreender o não-eu, é preciso encontrar um acesso através de uma entidade, através de uma essência abstrata que é e não é. Aí se dissolve a alteridade do Outro. O ser estranho, em vez de se manter na inexpugnável fortaleza da sua singularidade, em vez de fazer face - torna-se tema e objeto. Coloca-se já sob um conceito ou dissolve-se em relações. Cai na rede de ideias a priori, que emprego para captá-lo. (Levinas, 1999, p. 204)

O ensinamento levinasiano se constitui como descrição fenomenológica da resistência de Outrem aos poderes dominadores do Mesmo. Tal questionamento se dirige à própria razão ocidental, caracterizada como uma forma astuciosa de dominação e tirania. Pois a razão, ao apelar para uma ordem conceitual, acaba por violentar e desrespeitar a resistência que o Outro apresenta, colocando-o no âmbito do ser em geral. Na educação tradicional, pelo recurso ao conceito universal, a razão desrespeita as singularidades e, inevitavelmente, constrói uma totalidade. Ou seja, neste modelo de educação formal, pelo qual o singular passa ao universal, o Outro fica como que suspenso e privado de permanecer em sua alteridade, e acaba fazendo parte de um sistema total, ditando todas as regras, não lhe restando alternativa senão agir de acordo com as normas propostas pelo sistema.

Em relação a este sistema educacional dominador e tirânico, Levinas busca descrever um ordenamento ético-pedagógico situado para além do jogo astucioso da razão, que se caracteriza precisamente como luta e violência. A educação humanista constituída e estabelecida, por Levinas, mediante a ética não tem sua resistência rompida pela ordem do poder, da liberdade, isto é, do império da violência do saber. Uma vez que o sentido de Outrem escapa à referência ao ser e ao saber, institui-se uma espécie de pedagogia ética, entendida como relação respeitosa para com Outrem, ficando resguardada e valorizada a sua dimensão de Outro enquanto Outro - alteridade.

\section{Ensino metafísico como questionamento do ensino tradicional}

Como pudemos notar, um dos objetivos de Levinas é colocar em questão o primado da estrutura cognitiva vigente na filosofia e educação ocidentais, sobretudo, na fenomenologia e na ontologia. Em contraposição a este modelo tradicional de 
produção conhecimento, Levinas apresenta e descreve outro tipo de saber, que se fundamenta de modo crítico perante o dogmatismo reinante na tradição. Ora, o que é que põe em questão a teoria, a inteligibilidade enquanto redução e neutralização? E qual o seu sentido?

Em Levinas, o conhecimento é posto em questão mediante o conceito de Desejo (ensino, pedagogia ético-crítica). Nosso filósofo, ao retomar este tradicional conceito, diferencia-o da "aspiração" em Platão, do "apetite" no caso particular da escolástica e, sobretudo, do conceito de "desejo" empregado por Hegel, e dá-lhe uma interpretação particular. Neste empreendimento, Levinas (1993a, p. 55) inspira-se no comentário de Paul Valéry a Platão, onde o comentarista fala de um "desejo sem defeito", totalmente puro.

Em Totalidade e infinito (de 1961), Levinas apresenta o conceito de Desejo (Desir), contrapondo-o ao de necessidade. A diferença entre necessidade e Desejo, para a qual Levinas chama a atenção, reside no fato de que: "na necessidade, posso morder no real e satisfazer-me, assimilar o outro. No Desejo, não se morde no ser, não há saciedade, mas futuro sem balizas perante mim" (Levinas, 2000, p. 102). O Desejo - ensino ético-crítico - pressupõe um questionamento da liberdade, ao poder, à luz do conhecimento, exaltando uma precedência da ética frente à ontologia. Em Levinas, a defesa desta tese parte de uma dupla consideração sobre a pedagogia: por um lado, o saber pedagógico se refere a um tipo de relação em que os termos se conhecem, se respeitam e, principalmente, se mantêm na alteridade. Vale dizer, Levinas sustenta uma concepção originária de educação, entendida como relação em que o ser que conhece se manifesta ao ser conhecido, respeitando sua alteridade e não infligindo a ele a marca cognitiva da inteligibilidade como uma determinação em seu ser. "O saber ou a teoria (pedagogia) significa, em primeiro lugar, uma relação tal com o ser que o ser cognoscente deixa o ser conhecido manifestar-se, respeitando a sua alteridade e sem o marcar, seja no que for, pela relação de conhecimento". (Levinas, 2000, p. 29).

Por outro lado, Levinas enfatiza que o saber pedagógico, talvez não mais originariamente, mas ontologicamente, significa Logos do ser, ou seja, diz respeito à inteligibilidade do ser conhecido, em que, mediante o conceito neutro de ser, o Outro vem representado, domesticado e, consequentemente, abdicando de sua alteridade. Neste modelo educativo, a alteridade se esvai em identificação, restando apenas a representação na qual o Eu se apresenta como autônomo. A pedagogia como inteligência do ser, para nosso filósofo, foi o caminho seguido pela filosofia ocidental, dispensando a heteronomia como respeito pela alteridade, para priorizar a autonomia, a liberdade, a redução do Outro ao Mesmo. 
O ideal de ensino promovido pela filosofia ocidental se moveu, segundo Levinas, sempre baseado em uma busca de satisfação (necessidade).

A necessidade atesta o vazio e a falta no necessitado, a sua dependência em relação ao exterior, a insuficiência do ser necessitado, precisamente porque não possui de todo o seu ser e, por conseguinte, não está separado, em rigor de termos. Uma das vias da metafísica grega consistia em procurar o regresso à unidade. (Idem, ibid., p. 89-90)

Como vimos, o alvo do ensinamento de Levinas ou o ponto culminante das suas críticas é direcionado, sobretudo, à subjetividade transcendental de cunho identificativo, que evidencia um poder ontológico de autoapropriação, pela qual o Eu se preenche e se cumula com suas descobertas, suas posses, seu poder e, principalmente, com sua liberdade no ato de conhecimento, realizando um percurso e movimento pedagógicos de autoconstituição de significado e sentido, engendrados a partir de si e para si.

Entretanto, visualiza-se no ensinamento de Levinas um contraponto ao enaltecimento do papel gnoseológico da intencionalidade teórica, que apresenta e constitui uma subjetividade em relação com o Outro, porém nesta modalidade relacional a alteridade é assimilada e reduzida, formando, assim, uma estrutura educativa totalitária, isto é, que se engendra e se reduz a partir e ao estatuto do Mesmo (Alves \& Ghiggi, 2011). A atitude pedagógica de caráter representacional e mesmo o saber do ser, como instâncias de presença e de unidade, vêm coroar e responder a uma forma de satisfação das necessidades apenas do próprio Eu.

A educação tradicional (ontologia) como inteligência do ser remete à necessidade, que nasce de um Eu, e tende sempre à satisfação de uma defasagem interior. Esta defasagem renasce a cada satisfação, ocasionando sempre novas faltas e, consequentemente, nova satisfação, isto é, nova tensão por si mesmo, revelando-se como o "mal do retorno", que busca sempre a complementação.

A necessidade abre-se a um mundo que existe para mim - ela regressa a si. Mesmo sublime, como necessidade da salvação, é ainda nostalgia, saudade. A necessidade é o próprio regresso, a ansiedade do eu por si, forma original da identificação a que chamamos egoísmo. Ela é assimilação do mundo com vista à coincidência consigo mesmo ou felicidade. (Levinas, 1999, p. 233)

Na pedagogia do Mesmo, o Outro é subsumido e consumido pelo Eu, mediante a atividade intencional do pensamento que é motivado e despertado por um connatus (força, apetite), isto é, por uma necessidade que tende a se satisfazer e se preencher. O saber produzido por este tipo de relação apresenta-se como uma forma de gozo, de satisfação e de pontencialização da subjetividade como identidade que 
se descobre e conhece como poder e liberdade. O processo cognitivo, a partir do qual a filosofia moderna se enquadra e expressa, em sua busca da verdade, dá prova desse gozo e narcisismo teóricos.

Nesse sentido, em relação ao horizonte espontâneo do império das necessidades e da completude da identidade - pedagogia tradicional -, é que o Desejo ensino ético-crítico -, sempre e eternamente Desejo, vem contrapor-se, despertado e instigado neste momento pelo Outro como absolutamente Outro, acenando para a questão de outro estatuto educativo, qual seja: o horizonte ético.

A um sujeito virado para si mesmo que, segundo a fórmula estóica, é caracterizado pela tendência de persistir no seu ser (...), a um sujeito que se define assim pela inquietude de si - e que cumpre na felicidade o seu "para si mesmo" - opomos o Desejo do Outro que deriva de um ser já preenchido e independente, que não deseja para si. Necessidade daquele que já não tem necessidades - ele reconhece-se na necessidade de um Outro que Outrem, que nem é meu inimigo, nem meu complemento (...). O Desejo de Outrem nasce num ser a quem nada falta ou, mais exatamente, ele nasce para além de tudo o que lhe pode faltar ou satisfazê-lo. Esse Desejo de Outrem, que é a própria sociabilidade, não é uma simples relação com o ser em que, segundo as nossas fórmulas de partida, o Outro se converte em Mesmo. (Levinas, 1999, p. 233-234)

\section{Ética e educação: ensino - essência crítica do saber}

Ora, a contrapartida deste modelo não original de produção saber é o Desejo (Ensino), como essência ético-crítico do saber. "O Desejo Metafísico seria a essência da teoria" (Levinas, 2000, p. 29), uma vez que o ensinamento não parte do Eu, vem do Outro. Surge sempre em uma interioridade já contente, feliz na satisfação de suas necessidades. O Ensinamento, no sentido metafísico, apresentado por Levinas, não remete a uma saída que tende a um retorno, mas a um transbordamento, a uma abertura, a uma transcendência. Observa-se, no Ensino Metafísico, uma ruptura com o ideal imanentista, ou seja, evidencia-se uma transcendência irredutível à imanência. O saber, a teoria mediante a óptica do Ensino ético-crítico, significa uma relação do ser que conhece com o ser conhecido, onde o cognoscente permite que o conhecido se manifeste, respeitando a sua alteridade, a sua transcendência.

Ao que parece, Levinas apresenta uma distinção pedagógica entre o ser que conhece e o Mesmo que intelige, pois suspeita que a inteligibilidade e a representação não passem de neutralizantes e redutoras modalidades de conhecimento. $\mathrm{O}$ conhecimento para Levinas tem um caráter de relação, ao passo que a intelecção configura-se pelo caráter de constituição. Isto é, o ser que conhece, diferentemente do Eu que intelige, tem a possibilidade de não determinar o ser conhecido, de respeitar sua alteridade e de manifestar-se a ele. Mas o Mesmo que faz a intelecção sujeita 
o ser conhecido, constituindo-o, espacializando-o e temporalizando-o como objeto sujeitado e inteligido pelo Eu.

A educação, o saber, a teoria tomada em seu modo originário, ou ainda não distorcida como ontologia, inteligência dos entes a partir da face violenta do ser, Levinas chama de metafísica ou ética. Teorizar e conhecer os entes, metafisicamente, significa assumir uma atitude crítica em relação ao reducionismo da ontologia. Significa também resgatar dos entes o que não aparece como fenômeno à luz do ser e restabelecer a alteridade perdida, subsumida, reduzida pela inteligibilidade livremente exercida pelo Mesmo.

A teoria, como respeito da exterioridade, desenha uma outra estrutura essencial da metafísica. Tem a preocupação de crítica na sua inteligência de ser - ou ontologia. Descobre o dogmatismo e o arbitrário ingênuo da sua espontaneidade e não em questão a liberdade do exercício ontológico. (Levinas, 2000, p. 118)

O saber desenvolvido a partir do Ensino, como respeito (ética) pela exterioridade, desenha a estrutura crítica da educação, frente ao dogmatismo arbitrário e ingênuo da liberdade do exercício ontológico. Este Ensino ético-crítica situa-se para além da pedagogia como inteligência do ser (ontologia). Isto é, não reduz o Outro ao Mesmo, mas questiona esta estrutura balizada no ensino proveniente da mesmidade. Este questionamento não se dá na espontaneidade egoísta do Mesmo, pois é algo que se faz pelo Outro.

Da maneira que sua intenção crítica a leva para além da teoria e da ontologia: a crítica não reduz o Outro ao Mesmo como a ontologia, mas põe em questão o exercício do Mesmo. Um pôr em questão o Mesmo - que não pode fazer-se na espontaneidade egoísta do Mesmo - é algo que se faz pelo Outro. Chama-se ética a esta impugnação da minha espontaneidade pela presença de Outrem. A estranheza de Outrem - a sua irredutibilidade a Mim, aos meus pensamentos e às minhas posses - realiza-se precisamente como um pôr em questão da minha espontaneidade, como ética. A metafísica, a transcendência, o acolhimento do Outro pelo mesmo, de Outrem pelo Outro, isto é, como a ética que cumpre a essência crítica do saber. E tal como a crítica precede o dogmatismo, a metafísica precede a ontologia. (Idem, ibid., p. 30)

A metafísica como pedagogia crítica dos entes descobre o dogmatismo fenomenológico de um ser acima dos entes, que ilumina e que ao mesmo tempo se manifesta em sua própria luz. Descobre o círculo hermenêutico que parte do ser e termina no ser, que parte da identidade e termina na sua identidade, e que parte do Mesmo e termina no Mesmo. Descobre a espontaneidade de um eu que se impõe como objetivador e contextualizador de sentido, a partir de si próprio. Descobre um ente humano constituído subjetivamente como mônoda solipsista. Descobre, ainda, uma intersubjetividade por convenções, onde identidades são constituídas na forma 
da absoluta não relação a Outros. A pedagogia metafísica questiona tal liberdade, tal espontaneidade, tal ingenuidade, tal arbitrariedade e tal dogmatismo próprios dos exercícios ontológicos.

Portanto, o modelo de produção do conhecimento tradicional é posto em questão por Levinas, uma vez que este empreende uma espécie de negação do que é exterior ao pensamento. Assim, o modo a partir do qual o processo de construção do conhecimento realiza o seu percurso é descrito, por nosso pensador, como um movimento neutralizante, reducionista e possessivo. Ou seja, tradicionalmente, vigorou a pedagogia da posse, em que o Outro acaba inevitavelmente tornando-se meu, ou seja, é integrado e assimilado pelo registro do Mesmo, que detém as ferramentas (racionalidade, inteligibilidade) para efetuar o processo cognitivo e, assim, formar um escopo conceitual, proporcionando-lhe a ideia geral deste outro particular.

\footnotetext{
Conhecer é surpreender no indivíduo que se enfrenta (...). O conhecimento consiste em apreender o indivíduo que existe sozinho, não na sua singularidade, que não conta, mas na sua generalidade, a única em que há ciência. E aí começa todo o poder. A rendição das coisas exteriores à liberdade humana através da sua generalidade não significa apenas, inocentemente, a sua compreensão, mas também a sua apropriação, a sua domesticação, a sua posse. Só na posse o eu conclui a identificação do diverso. Possuir é manter a realidade desse outro que se possui, mas suspendendo precisamente a sua independência numa civilização refletida pela filosofia do Mesmo, a liberdade cumpre-se como riqueza. A razão que reduz o outro é uma apropriação e um poder. (Levinas, 1999, p. 204-205)
}

Diferentemente deste reducionismo, desta neutralização e desta assimilação em que o Mesmo possui o poder e a liberdade de tudo medir por suas categorias, inclusive a relação com o Outro homem, Levinas descreve uma Pedagogia, um Encontro com Outrem a partir de uma perspectiva ética. Esta modalidade de Ensino permite mostrar que a extensão do poder do Mesmo já se define por uma limitação, uma impossibilidade de reduzir totalmente o Outro.

Em Levinas, como descrevemos, o Ensino Metafísico implica uma essência crítica do saber. Assim, desperta outra modalidade do humano. Se, no mundo da pedagogia tradicional, temos um Eu que goza e faz do saber um poder, com a pedagogia ética temos um psiquismo que não se contém, que sente seu egocentrismo extrapolar-se, abala-se a sua identidade e completude, pois agora ele está direcionado à Alteridade. Em suma, o Ensino, para Levinas, é um choque, um traumatismo, uma afecção no mais profundo da subjetividade. É uma atração abismal que puxa o Eu para além do que se faz saber-se como Eu, para além de sua atividade de identificação na propriedade do próximo. O Ensinamento abre um mundo que se faz bondade, para além das lutas e posses encarniçadas dos indivíduos, é um acolhimento da Alteridade de Outrem que é maior e me precede. 
Esta afecção profunda que é o Ensinamento, este sentimento primordial, não surge senão despertado pelo Outro enquanto Outro, completamente exterior, o qual quebra a lógica do meu pensamento de totalização, evocando uma experiência ou uma relação social. Ora, a partir da educação ética, entramos na configuração do ser humano desejante, para além do âmbito da mera instintividade e animalidade. Vale dizer, para além da satisfação, do preenchimento, da complementação do conhecimento e, principalmente, da autonomia do Eu perante o mundo. É pelo Ensino que o Eu se oferece doando seu mundo a Outrem, viabilizando assim a concretização da ética, como relação respeitosa pela exterioridade de Outrem (Alves \& Ghiggi, 2012).

O Ensino ético não pode ser saciado, nem possui uma resposta concreta ou adequada, pois se situa para além da intencionalidade meramente teórica e do fenômeno visto e representado, ultrapassando preponderantemente o horizonte de integração no sistema meramente escolar. A educação é uma disposição ética pela qual o indivíduo se abre à transcendência, ou seja, é uma abertura que procura receber o Outro em sua exterioridade original. Esta abertura ética pressupõe um ser totalmente satisfeito e efetivamente constituído mediante o mundo e a consciência.

A educação e o mundo voltado somente ao serviço do Mesmo apresentam-se sem uma efetiva transcendência humana, pois, assim, estão somente direcionados para a administração e satisfação das necessidades que se vinculam ao sujeito necessitado. Neste caráter prestativo do mundo, as Alteridades são engendradas e "consumíveis" pelo Mesmo. Pode-se dizer que esta energia transmutada do Outro ao Mesmo, ou seja, esta assimilação do mundo como objeto, transforma-se em propulsão e, consequentemente, constitui concretamente o Mesmo. A necessidade tende ao mundo, porém a fruição deste perfila no retorno constante a si. Neste em vista de si, ou seja, neste em prol de sua solidificação, o Eu necessitado age envolvido por egoísmo e violência, que desrespeita a Alteridade do Outro, reduzindo-o ao meramente objetivável.

É esta energia colhida de Outrem que serve de motriz à consciência de si, à afirmação do Eu. Porém, esta consciência assimilativa pode correr o risco de permanecer enraizada na intencionalidade gozosa que se estende em teoria. Vale dizer, em transcendência na imanência, equiparando ética e ontologia. A pedagogia ética, diante da necessidade como constante retorno a si, em vista do preenchimento, da satisfação, instaura-se como um evento no sujeito identificativo, efetivando uma inversão do connatus, isto é, do curso da necessidade de satisfação em prol da bondade - educação.

Para que de fato ocorra um relacionamento humano e principalmente inter-humano, este encontro requer um esvaziamento da completude do Eu e o deslocamento do movimento centrípeto do eu. Somente assim se confirmará a singularidade 
de cada Eu separado e ateu, qualidades estas que permitem adentrar no âmbito da educação ética. O Ensino, como inquietude, provoca esvaziamento, que se estrutura a partir de uma permanente crítica à consciência egonômica, livre e espontânea. Portanto, o Ensinamento Metafísico é esta exigência de movimento do Mesmo que vai em direção do Outro e que jamais retorna ao Mesmo. Ou seja, exige uma generosidade radical, transcendência que se traduz em acolhimento e responsabilidade pelo Outro irredutível.

\section{Considerações finais}

Neste texto procuramos defender que Levinas, ao apresentar a ética como filosofia primeira, pretende resgatar o sentido ético-pedagógico da subjetividade, a partir da situação de Ensino como acolhimento da fala docente da Alteridade. A relação com Outrem ou comunicação é uma relação não alérgica, uma relação ética, e este discurso acolhido é um Ensinamento. Contudo, o Ensinamento não surge da maiêutica, vem do exterior, do Outro, e traz mais do que o eu contém em si mesmo. $\mathrm{O}$ acolhimento da fala de Outrem é para Levinas sinônimo de Ensino. Ou seja, a constituição do mundo social, cultural e intelectual como obra do poder e da iniciativa de consciência monológica é precedida pelo encontro com uma realidade exterior que não foi significada e nem constituída pelo trabalho da consciência, mas que é produto da relação inter-humana.

A situação de Ensino, descrita fenomenologicamente por Levinas, pressupõe o face a face da linguagem, isto é, a relação em que o Mesmo acolhe o Outro, sem que este último abdique de sua Alteridade, ou sua condição de único. Em suma, nenhum sistema teórico-conceitual ou regime sócio-político podem abarcar e neutralizar, de modo fechado, esta relação. Ao contrário, graças à situação de Ensino que se chega ao significado ético-crítico do saber e da teoria. Portanto, o Ensino supõe uma distância, uma impossibilidade de objetivação e de domínio do Outro pelo Mesmo.

Levinas se preocupa em descrever a relação com o Outro como Ensino, desde um acolhimento que não se encontra à medida do eu. Outrem, o estrangeiro, o aluno é aquele que abala, desestabiliza e questiona eticamente a boa consciência de um $\mathrm{Eu}$, do professor. No Ensino se pode pensar mais do que a capacidade constituinte permite. Isto é, pode-se pensar o estrangeiro, o transcendente, mas este pensar não é sinônimo nem de objetivação nem de compreensão. Isto porque, em Levinas, pensar é, em certo sentido, falar, ou seja, responder a Outrem. Que tipo de fenomenologia poderá descrever a situação de Ensino? Quais as consequências do Ensino para o resgate do sentido ético-pedagógico da subjetividade? 
Para Levinas, não se trata, apenas, de pensar e interagir com os outros, mas, sobretudo, de falar a eles. Falar a Outrem supõe uma convocação à palavra. Ser solicitado a falar implica a possibilidade de se fazer presente. Vale dizer, dirigir a palavra a Outrem supõe o desejo de uma resposta. O acolhimento do interlocutor, muito além de qualquer atividade sintética imanente à consciência, é o que torna possível uma orientação e uma ordem. O Outro é o Mestre, na medida em que põe fim à anarquia dos fatos e dos saberes. Outrem é o responsável por toda apresentação do mundo a mim. Por conseguinte, é ele que faz da atividade sintética uma relação de Ensino, mediante a qual é possível encontrar o princípio de orientação necessário para evitar a prisão no labirinto dos fatos.

O processo de identificação, em Levinas, perde sua primazia em função da ética, pois o mundo só se abre como tema na medida em que reconhecemos que o Outro é sinônimo de Maestria. O princípio de toda orientação vem de Outrem. Nas palavras do próprio Levinas (2000, p. 60): “só o absolutamente estranho nos pode instruir". Uma fenomenologia do Ensino é mais do que um repensamento de si a partir da relação com o diferente, pois o que se produz, no encontro com o estrangeiro, é um questionamento ético de toda obra de autoidentificação. Portanto, sustentamos que, se existe uma fenomenologia do Ensino em Levinas, ela deve ser pensada em sua ligação profunda com a ética.

\section{Nota}

1. Levinas (2000, p. 28) propõe que se chame de religião o "traço que se estabelece entre o Mesmo e o Outro, sem constituir uma totalidade".

\section{Referências}

ALVES, M.A.; GHIGGI, G. Levinas e a educação: da pedagogia do mesmo à pedagogia da alteridade. Revista Sul-Americana de Filosofia e Educação, Brasília, DF, n. 15, p. 95-111, 2011.

ALVES, M.A.; GHIGGI, G. Educação como encontro inter-humano: da ética do diálogo à resposta ética pela alteridade. Revista Sul-Americana de Filosofia e Educação, Brasília, DF, n. 17, p. 59-77, 2012.

COSTA, M.L. Levinas: uma introdução. Petrópolis: Vozes, 2000.

FABRI, M. Desencantando a ontologia. Porto Alegre: Edipucrs, 1997.

FABRI, M. Sentido ético e compreensão: em torno da questão levinasiana "a ontologia é fundamental"? Cadernos da Subjetividade, São Paulo, v. 5, n. 1, p. 53-69, 1997. 
FABRI, M. A ética como dessacralização em Levinas. Veritas, Porto Alegre, v. 46, n. 2, p. 295-302, 2001.

FABRI, M. Linguagem e desmistificação em Levinas. Síntese, Belo Horizonte, v. 28, n. 91, p. 245-266, 2001.

HEIDEGGER, M. Ser e tempo. Trad. Márcia de Sá Cavalcante. Petrópolis: Vozes, 1988. 2v.

LEVINAS, E. De otro modo que ser, o más allá de la esencia. Trad. Antonio Pintor-Ramos. Salamanca: Sígueme, 1987.

LEVINAS, E. Ética e infinito. Trad. João Gama. Lisboa: Ediciones 70, 1988.

LEVINAS, E. Transcendência e inteligibilidade (1984). Trad. José Freie Colaço. Lisboa: Ediciones 70, 1991.

LEVINAS, E. Humanismo do outro homem. Trad. Pergentino S. Pivatto. Petrópolis: Vozes, 1993a.

LEVINAS, E. El tiempo y el otro. Trad. José Luis Pardo Torío. Barcelona: Paidós, 1993b.

LEVINAS, E. Dios, la muerte y el tiempo (1993). Trad. Maria L. R. Tapia. Madrid: Cátedra, 1994.

LEVINAS, E. Entre nós: ensaio sobre a alteridade (1991). Trad. Pergentino S. Pivatto. Petrópolis: Vozes, 1997.

LEVINAS, E. Descobrindo a existência com Husserl e Heidegger (1949). Trad. Fernanda Oliveira. Lisboa: Instituto Piaget, 1999.

LEVINAS, E. Totalidade e infinito: ensaio sobre a exterioridade. Trad. José Pinto Ribeiro. Lisboa: Ediciones 70, 2000.

LEVINAS, E. De Deus que vem a ideia. Trad. Pergentino S. Pivatto. Petrópolis: Vozes, 2002. LÓPES, J.M.A. Trascendencia y alteridad: estudio sobre E. Levinas. Pamplona: Universidad de Navarra, 1992.

PELIZZOLI, M.L. A relação ao outro em Husserl e Levinas. Porto Alegre: Edipucrs, 1994. PIVATTO, P.S. A ética de Levinas e o sentido humano: crítica à ética ocidental e seus pressupostos. Veritas, Porto Alegre, v. 37, n. 147, p. 325-363, 1992.

PIVATTO, P.S. Responsabilidade e culpa em Levinas. Cadernos da Fafimc, Viamão, n 19, p. 87-107, 1998.

PIVATTO, P.S. Ser moral ou não ser humano. Veritas, Porto Alegre, v. 44, n. 2, p. 353367, 1999. 
POIRIÉ, F. Emmanuel Levinas: qui êtes-vous? Lyon: La Manufacture, 1987.

SOUZA, R.T. Sujeito, ética e história. Porto Alegre: Edipucrs, 1999.

SOUZA, R.T. Sentido e alteridade: dez ensaios sobre o pensamento de E. Levinas. Porto Alegre: Edipucrs, 2000.

SUSIN, L.C. O homem messiânico: uma introdução ao pensamento de E. Levinas. Porto Alegre: EST; Petrópolis: Vozes, 1984.

SUSIN, L.C. Levinas e a reconstrução da subjetividade. Veritas, Porto Alegre, v. 37, n. 147 , p. 365-377, 1992.

Recebido em 12 de julho de 2010.

Aprovado em 27 de dezembro de 2011. 